\title{
Effect of Antihyperglycemic Agents on Hemoglobin A1c Level in Type 2 Diabetes Mellitus Patients
}

\author{
Tasya Kamila, ${ }^{1}$ Vycke Yunivita Kusumah Dewi, ${ }^{2}$ Miftahurachman ${ }^{3}$ \\ ${ }^{1}$ RSUD Mampang Prapatan Jakarta, Indonesia, ${ }^{2}$ Department of Basic Medicine Faculty of \\ Medicine, Universitas Padjadjaran, Indonesia, ${ }^{3}$ Department of Internal Medicine Faculty of \\ Medicine Universitas Padjadjaran/Dr. Hasan Sadikin General Hospital Bandung, Indonesia
}

\begin{abstract}
Background: Type 2 diabetes mellitus (T2DM) patients require continuous lifelong attention to pharmacotherapy to achieve and maintain optimal glucose control, which can be monitored through measuring HbA1c. This study aimed to see the comparrison of HbA1c levels before and after a minimum of two months use of antihyperglycemic agents in patients with T2DM.

Methods: This analytical cross-sectional study used medical records of patients with T2DM in the center of outpatient medical records at the Department of Clinical Pathology, Dr. Hasan Sadikin General Hospital, in 2013. Sampling was conducted using consecutive sampling technique. The data analysis used the paired t-test and Wilcoxon test for not normal data distribution.

Results: Before and after a minimum of two months use of antihyperglycemic agents, HbA1c concentration was 7.15\% (6.1-12.2) and 7.3\% (5.9-11.9) respectively. Statistically, the difference of HbA1c concentration of T2DM patients between those period was not significant $(0.15 \% ; p=0,812)$. Mean HbA1c concentration was found with greatest decrease in patients treated with sulfonylurea $(2.25 \%)$, followed by insulin $(0.1 \%)$. There were increases in mean HbA1c concentration in patients treated with metformin $(0.05 \%)$, metformin+insulin $(1.1 \%)$, sulfonylurea +metformin $(0.6 \%)$, sulfonylurea+alpha-glucosidase inhibitor $(1.1 \%)$, and sulfonylurea + metformin + alpha-glucosidase inhibitor $(0.05 \%)$.

Conclusions: There is no significant difference of HbA1c levels before and after two months to two years use of antihyperglycemic agents in T2DM patients. This result showed the importance of comprehensiveness in T2DM therapy. The therapy should not merely consist of antihyperglycemic medication alone, but also physical exercise, lifestyle modification, and diet control.
\end{abstract}

Keywords: Antihyperglycemic agents, diabetes mellitus, HbA1c

\section{Introduction}

Diabetes mellitus is one of the noncommunicable diseases (NCD) which will be the cause of increase in mortality in the next decade. $^{1}$ Indonesia ranked seventh as the country with the highest number of diabetes patients in 2012. Prevalence of diabetes mellitus in Indonesia kept increasing in the last 30 years and recently become the third leading cause of death in Indonesia. It is estimated that with this growing prevalence, diabetes mellitus will put huge burden and challenges to the Indonesian healthcare system. ${ }^{2}$

Type 2 Diabetes Mellitus (T2DM) is characterized by insulin resistance that leads intoastate ofhyperglycemia.Highbloodglucose concentrations if left untreated can increase the risk of acute and chronic complications. Hence, T2DM patients require lifelong scrutiny to lifestyle and pharmacotherapy, which is an antihyperglycemicagent, to attain and maintain optimal glucose control. ${ }^{3}$ The effect of lifestyle and pharmacotherapy to glucose levels can be monitored by measuring blood glucose and HbA1c. Besides HbA1c a glycated hemoglobin is the recommended measurement as it can describe both fasting and postprandial glucose concentrations within six to twelve weeks. ${ }^{4,5}$ Antihyperglycemic agents have effects that persisted for up to two years in lowering HbA1c levels. ${ }^{6}$

Correspondence: Tasya Kamila, RSUD Mampang Prapatan, Jalan Kapten Tendean No. 9, Mampang Prapatan, Jakarta Selatan, Indonesia, Email: tasyakamila94@gmail.com 
According to the American Diabetes Association (ADA) and Indonesian Society of Endocrinology (Perkumpulan Endokrinologi Indonesia, PERKENI), the HbA1c target for patients with T2DM is less than 7\%.,7 Previous studies conducted in 2003 and 2010 showed that more than half of the patients with T2DM in primary health cares in Indonesia ${ }^{8}$ and the Endocrine Clinic of Dr. Hasan Sadikin Hospital General Hospital ${ }^{9}$ did not reach the HbA1c target. However, these studies could not conclude that the vast majority of diabetic treatment was unsuccessful because they ignored the time when the measurement of HbA1c was performed, which may result in higher HbA1c measurement if performed at least two months prior to the antihyperglycemic medication. Therefore, the purpose of this study was to analyze the difference in HbA1c before and after two months to two years use of antihyperglycemic agents in patients with T2DM.

\section{Methods}

This analytical cross-sectional study used the medical records of patients with type 2 diabetes mellitus dated 1 January-31 December 2013 at the Endocrine Outpatient Clinic of Dr. Hasan Sadikin General Hospital (RSHS),
Bandung, Indonesia. Data were collected using consecutive sampling technique from September to October 2014. The used of medical records had been approved by the Health Research Ethics Committee of RSHS. Medical records that had HbA1c measurement data before and after two months to two years use of antihyperglycemic agents met the inclusion criteria. Medical records with a history of abnormal bleeding in two to three months prior to HbA1c measurement, as it may mask low in HbA1c levels, were excluded. Data of antihyperglicemic medications collected were the latest antihyperglycemic agents prescribed by the physician. The HbA1c measurement was performed by the Department of Clinical Pathology of RSHS.

Furthermore, data of antihyperglycemic medication and HbA1c level before and after a minimum of two months use of antihyperglycemic agents were used in the analysis. Additionally, types of antihyperglycemic agents, the patient's age, and the number of months between the last visits were used as descriptive data.

Moreover, the analysis of differences in HbA1c level before and after a minimum of two months use of antihyperglycemic agents in patients with type 2 diabetes mellitus was performed using the paired t-test and non-parametric Wilcoxon test if the data

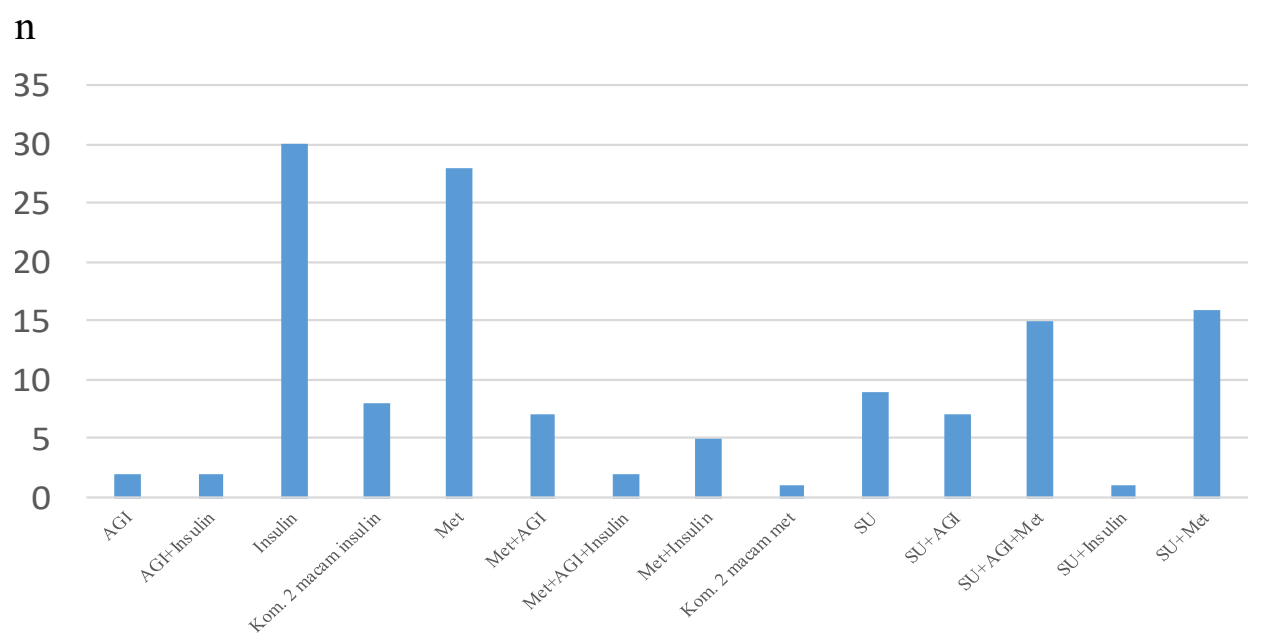

Drug class

Figure 1 Characteristics of Antihyperglycemic Agents Used in Type 2 Diabetes Mellitus Patients of Endocrine Outpatient Clinic, Dr. Hasan Sadikin General Hospital, Period 2013

Notes: $\mathrm{SU}=$ Sulfonylurea; Met = Metformin; AGI = Alpha-glucosidase Inhibitor; $\mathrm{n}$ = number of patients 
Table 1 Sociodemographic Characteristic and Punctuality Control

\begin{tabular}{|c|c|c|c|c|c|c|c|c|}
\hline \multirow[t]{2}{*}{ Parameter } & \multicolumn{8}{|c|}{$\begin{array}{c}\text { Antihyperglycemic class } \\
\text { n(\%) }\end{array}$} \\
\hline & SU+Met & $\mathrm{SU}+\mathrm{AGI}$ & SU & $\mathrm{SU}+\mathrm{AGI}+\mathrm{Met}$ & Insulin & Met & Met+Insulin & Total \\
\hline \multicolumn{9}{|l|}{ Gender } \\
\hline Male & $0(0)$ & $0(0)$ & $1(50)$ & $0(0)$ & $1(50)$ & $0(0)$ & $0(0)$ & $2(10)$ \\
\hline Female & $8(100)$ & $3(100)$ & $1(50)$ & $2(100)$ & $1(50)$ & $2(100)$ & $1(100)$ & $18(90)$ \\
\hline \multicolumn{9}{|l|}{ Age Group } \\
\hline $41-50$ & $2(25)$ & $1(33)$ & $0(0)$ & $0(0)$ & $0(0)$ & $0(0)$ & $1(100)$ & $4(20)$ \\
\hline $51-60$ & $2(25)$ & $1(33)$ & $2(100)$ & $0(0)$ & $1(50)$ & $0(0)$ & $0(0)$ & $6(30)$ \\
\hline $61-70$ & $4(50)$ & $1(33)$ & $0(0)$ & $2(100)$ & $1(50)$ & $2(100)$ & $0(0)$ & $10(50)$ \\
\hline \multicolumn{9}{|l|}{ Control time } \\
\hline Timely & $5(62.5)$ & $1(33)$ & $1(50)$ & $2(100)$ & $1(50)$ & $1(50)$ & $1(100)$ & $12(60)$ \\
\hline Not timely & $3(37.5)$ & $2(66)$ & $1(50)$ & $0(0)$ & $1(50)$ & $1(50)$ & $0(0)$ & $8(40)$ \\
\hline
\end{tabular}

distribution was not normal. The analyses were performed using analysis software. The minimum $\mathrm{HbA1c}$ difference between before and after use of antihyperglycemic agents was statistically significant if $\mathrm{p} \leq 0.05$.

\section{Results}

A total of 137 medical records were successfully collected. Figure 1 showed the characteristics of antihyperglycemic agents used in type 2 diabetes mellitus patients.

Furthermore, 14 types of antihyperglycemic agent prescribed with insulin were the most agents prescribed. Fourteen types of antihyperglycemic agents prescribed can be grouped into larger groups, namely monotherapy (38.5\%), a combination of two oral hypoglycemic drugs (OHA) (23.4\%), a combination of three OHAs $(11.3 \%)$, one OHA + insulin (6.1\%), a combination of two OHAs + insulin (1.5\%), and insulin (28.6). From these groups, monotherapy was the most given therapy.
There were 20 medical records that met the inclusion and exclusion criteria. Characteristics of antihyperglycemic agents that met the inclusion and exclusion criteria, as well as their sociodemographic characteristics and timeliness of patients' control showed that most of the samples were female and aged 61-70 years (Table 1). Based on the data in the collected medical records, the physician would prescribe antihyperglycemic agents that would be used up in 3 months if taken appropriately as directed by the physician. Patients who visited the doctor within a period of less than or equal to 3 months after the last visit was said to be timely control, while patients who visited the doctor within a period of more than 3 months was said to be not timely control. Overall, the majority of patients was timely control. However, the patients with Sulfonylurea+Alpha-glucosidase inhibitors prescribed medication tended to be not timely control.

Moreover, $\mathrm{HbA} 1 \mathrm{c}$ data at before and after two months to two years of antihyperglycemic

Table 2 HbA1c Difference Before and After 2 Months to 2 Years of Antihyperglycemic Medication

\begin{tabular}{lccc}
\hline \multicolumn{1}{c}{ HbA1c level } & $\mathbf{n}$ & $\begin{array}{c}\text { Median } \\
\text { (minimum-maximum) }\end{array}$ & p \\
\hline $\begin{array}{l}\text { HbA1c before antihyperglycemic medication } \\
\text { HbA1c after 2 months to 2 years of }\end{array}$ & 20 & $7.15 \%(6.1-12.2)$ & 0.812 \\
antihyperglycemic medication & 20 & $7.3 \%(5.9-11.9)$ & \\
\hline
\end{tabular}

Notes: $\mathrm{p}=$ probability 
Table 3 Characteristics of Hba1c Concentrations for Drug Classes, Punctuality of Control, and Age Groups

\begin{tabular}{|c|c|c|c|c|c|}
\hline \multirow[b]{2}{*}{ Parameter } & \multirow[b]{2}{*}{$\mathbf{n}$} & \multicolumn{2}{|c|}{ Median HbA1c } & \multirow[b]{2}{*}{$\Delta$} & \multirow[b]{2}{*}{$\mathbf{p}$} \\
\hline & & $\begin{array}{c}\text { Before medication } \\
(\%)\end{array}$ & $\begin{array}{c}\text { After minimum } \\
2 \text { months of } \\
\text { medication } \\
(\%)\end{array}$ & & \\
\hline \multicolumn{6}{|l|}{ Drug Class } \\
\hline SU & 2 & 9.25 & 7 & 2.25 & - \\
\hline SU+Met & 8 & 6.95 & 7.55 & 0.6 & - \\
\hline SU+Met+AGI & 3 & 6.95 & 7 & 0.05 & - \\
\hline $\mathrm{SU}+\mathrm{AGI}$ & 2 & 10.6 & 11.7 & 1.1 & - \\
\hline Met & 2 & 6.85 & 6.9 & 0.05 & - \\
\hline Insulin & 2 & 8.1 & 8 & 0.1 & - \\
\hline Met+Insulin & 1 & 6.1 & 7.2 & 1.1 & - \\
\hline \multicolumn{6}{|l|}{ Control Time } \\
\hline Timely & 12 & 7.15 & 7.3 & 0.15 & 0.2 \\
\hline Not timely & 8 & 8.6 & 8 & 0.6 & 0.49 \\
\hline \multicolumn{6}{|l|}{ Age group } \\
\hline $41-50$ & 4 & 8.65 & 10.75 & 2.1 & 0.273 \\
\hline $51-60$ & 6 & 8.9 & 8.4 & 0.5 & 0.893 \\
\hline $61-70$ & 10 & 6.8 & 6.95 & 0.15 & 0.399 \\
\hline
\end{tabular}

Table 4 Treatment Success (Based upon PERKENI's Hba1c Recommended Goals for T2DM Patients)

\begin{tabular}{|c|c|c|c|c|c|}
\hline \multirow{3}{*}{ Antihyperglycemic agent } & \multicolumn{4}{|c|}{ HbA1c goals achievement } & \multirow{3}{*}{ Tota } \\
\hline & \multicolumn{2}{|c|}{ Attain $(\mathrm{HbA1c}<7 \%)$} & \multicolumn{2}{|c|}{ Fail $(H b A 1 c \geq 7 \%)$} & \\
\hline & $\mathbf{n}$ & $\%$ & $\mathbf{n}$ & $\%$ & \\
\hline SU & 1 & 5 & 1 & 5 & 2 \\
\hline SU+Met & 3 & 15 & 5 & 25 & 8 \\
\hline SU+Met+AGI & 0 & 0 & 3 & 15 & 3 \\
\hline $\mathrm{SU}+\mathrm{AGI}$ & 1 & 5 & 1 & 5 & 2 \\
\hline Met & 1 & 5 & 1 & 5 & 2 \\
\hline Insulin & 1 & 5 & 1 & 5 & 2 \\
\hline Met+Insulin & 0 & 0 & 1 & 5 & 1 \\
\hline Total & 7 & 35 & 13 & 65 & 20 \\
\hline
\end{tabular}


medication showed abnormal data distribution using the Shapiro-Wilk test. Data were analyzed using the Wilcoxon test and found that the difference in HbA1c between before and after two months to two years of antihyperglycemic medication was not statistically significant ( $\mathrm{p}=0.812$ ) (Table 2$)$.

Data of the characteristics of HbA1c concentrations for drug classes, punctuality of control, and age groups showed that the concentration of $\mathrm{HbA} 1 \mathrm{c}$ prior taking antihyperglycemicmedicationsvaryineachtype of drug, punctuality of control, and age groups. Additionally, administration of combination of three OHA (Sulfonylurea+Alpha-glucosidase Inhibitor+metformin) resulted in the highest median HbA1c concentration. There was a decrease in HbA1c between before and after two months to two years use of Sulfonylurea and Metformin. HbA1c concentration before and after taking antihyperglycemic medications tended to be low in timely control patients compared to not timely control patients. HbA1c decreased in the 51-70 age group while experienced an increase in the 41-50 age group (Table 3 ).

The treatment success based upon PERKENI's HbA1c recommended goals for T2DM patients, namely the treatment of type 2 diabetes was considered to have failed when the patients did not attain HbA1c less than $7 \%$ after 2-3 months of medication. Overall, the majority of patients (65\%) did not attained the recommended goals of HbA1c (Table4).

\section{Discussion}

This study discovered that the types of OHA prescribed at RSHS's Endocrine Outpatient Clinic was Sulfonylurea, Alpha-Glucosidase Inhibitor, and Metformin. Recently, there are various types of OHA available that have fewer side effects with great benefits for patients with type 2 diabetes, for example Glucagonlike polypeptide-1 (GLP-1) receptor antagonist and dipeptidyl peptidase-4 (DPP-4) inhibitors. 10 As the vast majority of T2DM patients in RSHS's Endocrine Outpatient Clinic did not attain recommended goals of $\mathrm{HbA1c}$, other types of OHA could be taken into consideration.

The majority of patients were with type 2 diabetes control timely. However, patients given Sulfonylurea+Alpha-glucosidase inhibitors tended to not control timely. This can be due to the discomfort the patient felt because of the side effects caused by Sulfonylurea and Alpha-glucosidase inhibitors, i.e. moderatesevere hypoglycemia, increased body weight, and gastrointestinal side effects. ${ }^{10}$ The impact of delayed time control may be the reason why HbA1c goals were not attained.

The difference in median HbA1c before and after at least 2 months of medication was not statistically significant $(0.15 \% ; p=0.812)$. This result was not in accordance with the previous systematic review and meta-analysis of double-blinded, randomized controlled trials of antihyperglycemic agents, which indicates that the use of AGI, Metformin, and SU each can reduce HbA1c by approximately 1 to $1.25 \%$ when compared with placebo. 6 Insulin can reduce $\mathrm{HbA1c}$ by approximately 1.5 to $3.5 \% .^{7}$ This discrepancy may occur due to the different sample size and showed that the management given to T2DM patients in clinical practice was not comprehensive, such as low encouragement in implementing diet control, physical exercise, and healthy lifesytle in addition to the use of antihyperglycemic agents.

Less aggressive therapy intensification and lack of attention to a healthy lifestyle can lead to median HbA1c difference between before and after minimum of two months of antihyperglycemic medication were not significant. ${ }^{11}$ The American Association of Clinical Endocrinologists (AACE) in glycemic control algorithm publication in 2013 suggested toraising the treatment to the next step if $\mathrm{HbA} 1 \mathrm{c}$ goal is not attained after three months of treatment. ${ }^{10}$ In addition to the use of antihyperglycemic agents, ADA's and PERKENI's type 2 diabetes mellitus therapeutic algorithm emphasis on the practice of healthy lifestyle. $^{3,7}$ Lifestyle management consists of reducing excess body weight through caloric restriction, limiting sodium intake below $2.300 \mathrm{mg} /$ day, increasing consumption of fruits, vegetables and low-fat dairy products, avoiding excessive alcohol consumption, and increasing physical activities. ${ }^{11}$ The practice of healthy lifestyle has a great effect on body mass index (BMI). A retrospective cohort study conducted in overweight and obesse patients with type 2 diabetes showed the importance of weight loss to achieve the treatment goal, which for every $10 \%$ intentional weight loss by calorie-restricted diet, the estimated reduction in $\mathrm{HbA} 1 \mathrm{c}$ concentration is $0.81 \%{ }^{12}$ However, most patients still considered practice of healthy lifestyle less important. A study showed that the majority of patients with type 2 diabetes who were given lifestyle intervention alone did not return for follow-up compared with patients who were prescribed drug. ${ }^{13}$ It is necessary to emphasis the 
importance of healthy lifestyle to patients with type 2 diabetes so that treatment goals can be achieved.

In addition to doctor's efforts in treatment intensification and healthy lifestyles education, there is another attempt to attain the treatment goal of patients with type 2 diabetes mellitus, for example with diabetes self-management education (DSME). DSME is an ongoing process to facilitate diabetic patients with the knowledge, skills, and abilities necessary for self-care. One study showed a significant decrease in HbA1c concentration in patients with type 2 diabetes mellitus with DSME compared with routine treatment. ${ }^{14}$

Basically HbA1c concentration in the blood is determined by the concentration of glucose in the blood and life span of red blood cells. Thus in some cases the levels of HbA1c does not truly describe the longterm glycemic control in patients. Several factors are known to influence the outcome of the HbA1c measurement as triglycerides levels, bilirubin levels, chronic liver disease, hemoglobinopathy, iron deficiency, vitamin B 12 deficiency, blood urea levels, alcoholism, and the consumption of drugs such as aspirin and opiates. ${ }^{15,16}$ The existence of these factors was not completely written in the medical record, thus these factors may also caused insignificant differences in median $\mathrm{HbA1c}$ before and after two months to two years.

Additionally, HbA1c levels before starting antihyperglycemic medication varied in each type of antihyperglycemic agent, punctuality control, and age groups (Table 3). This also may caused the difference in median HbA1c varied in every type of antihyperglycemic agent, punctuality control, and age groups. Every 1\% higher baseline HbA1c concentrations, cause greater $0.01 \%$ decreases in $\mathrm{HbA1c}$ after three months antihyperglycemic medication. ${ }^{6}$ Due to the limitations of this study, i.e. the small sample size, HbA1c baseline group division was not performed. This study was only intended to analyze the treatment of type 2 diabetes in clinical practice, it could not be used as a reference for what type of antihyperglycemic agent had the best effect.

PERKENI stated the therapy is said to fail when the T2DM patient did not attain the goal of $\mathrm{HbA} 1 \mathrm{c}<7 \%$ after $2-3$ months of therapy. Approximately $65 \%$ of medical records did not reach the target (Table 4). These data confirmed a previous study conducted at RSHS in 2010 which claimed more than 50\% of patients with type 2 diabetes do not attain HbA1c goal. ${ }^{9}$ The same condition did not only happen in Indonesia. A larger study conducted involving 21,267 diabetic patients in Hawaii showed that despite good adherent to their medications, $56.1 \%$ of patients with type 2 diabetes mellitus do not meet the target HbA1c of less than $7 \% .^{17}$

This study concludes that there is no significant difference of HbA1c levels between before and after two months to two years use of antihyperglycemic agents in T2DM patients. Diabetes mellitus is a complex, chronic, and progressive metabolic disease influenced by social, behavior, and environmental factors. Increasing insulin resistance and declining in $\beta$-cell function from time to time resulting in lower glycemic control. ${ }^{3}$ Therefore, a gradual and thorough treatment, i.e. a healthy lifestyle and the use of antihyperglycmeic agents, is necessary to control blood glucose.

\section{References}

1. Alwan A, Armstrong T, Bettcher D, Branca F, Chisholm D, Ezzati M, et al. Global status report on noncommunicable diseases 2010. Italy: WHO; 2011.

2. Soewondo P, Ferrario A, Tahapary DL. Challenges in diabetes management in Indonesia: a literature review. Globalization Health. 2013;9:63.

3. Nathan DM, Buse JB, Davidson MB, Ferrannini E, Holman RR, Sherwin R, et al. Medical management of hyperglycemia in type 2 diabetes: a consensus algorithm for the initiation and adjustment of therapy: a consensus statement of the American Diabetes Association and the European Association for the Study of Diabetes. Diabetes Care. 2009;32(1):193-203.

4. Kennelly PJ, Rodwell VW. Proteins: myoglobin \& hemoglobin. In: Murray RK, Bender DA, Botham KM, Kennelly PJ, Rodwell VW, Weil PA, editors. Harper's illustrated biochemistry. 28th ed. United States: The McGraw-Hill Companies, Inc; 2009.

5. Sikaris K. The correlation of hemoglobin A1c to blood glucose. J Diabetes Sci Technol. 2009;3(3):429-38.

6. Sherifali D, Nerenberg K, Pullenayegum E, Cheng JE, Gerstein HC. The Effect of Oral Antidiabetic Agents on A1C Levels: A systematic review and meta-analysis. Diabetes Care. 2010;33(8):1859-64.

7. Perkumpulan Endokrinologi Indonesia. Konsensus pengendalian dan pencegahan diabetes mellitus tipe 2 di Indonesia 2011. Jakarta: PB PERKENI; 2011. 
8. Soegondo S, Prodjosudjadi W, Setiawati A. Prevalence and risk factors for microalbuminuria in a cross-sectional study of type- 2 diabetic patients in Indonesia: a subset of DEMAND study. Med J Indones. 2009;18(2):124-30.

9. Kusniyah Y, Nursiswati, Rahayu U. Hubungan Tingkat Self Care dengan Tingkat Hba1c pada Klien Diabetes Melitus Tipe 2 di Poliklinik Endokrin RSUP Dr. Hasan Sadikin Bandung. Bandung: Universitas Padjadjaran; 2016. [cited 2018 May 15] Available from: http://repository. unpad.ac.id/8976/

10. Garber AJ, Arbahamson MJ, Barzilay JI, Blonde L, Bloomgarden ZT, Bush MA, et al. American Association of Clinical Endocrinologists' comprehensive diabetes management algorithm 2013 consensus statement--executive summary. Endocr Pract. 2013;19(3):536-57.

11. American Diabetes Association. Standards of medical care in diabetes. Diabetes Care. 2018;41(Supplement 1):S1-2.

12. Shantha GP, Kumar AA, Kahan S, Cheskin LJ. Association between glycosylated hemoglobin and intentional weight loss in overweight and obese patients with type
2 diabetes mellitus: a retrospective cohort study. Diabetes Educ. 2012;38(3):417-26.

13. Reinehr T, Schober E, Roth CL, Wiegand S, Holl R. Type 2 diabetes in children and adolescents in a 2-year follow-up: insufficient adherence to diabetes centers. Horm Res. 2008;69(2):107-13.

14. Steinsbekk A, Rygg Lø, Lisulo M, Rise MB, Fretheim A. Group based diabetes self-management education compared to routine treatment for people wit type 2 diabetes melitus. A Systemic Review with Meta-analysis. BMC Health Serv Res. 2012;12:213.

15. Unnikrishnan R, Anjana RM, Mohan V. Drugs affecting $\mathrm{HbA1c}$ levels. Indian J Endocrinol Metab. 2012;16(4):528-31.

16. Gallagher EJ, Le Roith D, Bloomgarden Z. Review of hemoglobin $A(1 c)$ in the management of diabetes. J Diabetes. 2009;1(1):9-17.

17. Juarez DT, Ma C, Kumasaka A, Shimada R, Davis J. Failure to reach target glycated A1c levels among patients with diabetes who are adherent to their antidiabetic medication. Popul Health Manag. 2014;17(4):218-23. 